\title{
TRATAMENTO INDUSTRIAL E PRÉ-INOCULAÇÃO DO MILHO COM Azospirillum spp.: POTENCIAL FISIOLÓGICO DAS SEMENTES E PRODUTIVIDADE
}

\author{
LUCAS CAIUBI PEREIRA ${ }^{1}$, LARISSA VINIS CORREIA ${ }^{1}$, ALESSANDRO LUCCA BRACCINI ${ }^{1}$, \\ DANILO CESAR VOLPATO MARTELI ${ }^{1}$, THAISA CAVALIERI MATERA ${ }^{1}$, \\ RENATA CRISTIANE PEREIRA ${ }^{1}$ e ANDREIA KAZUMI SUZUKAWA ${ }^{1}$
}

'Universidade Estadualde Maringá,lucascaiubi@yahoo.com.br,larissa.vinis@gmail.com,albraccini@uol.com.br, danilomartelli@hotmail.com, thaisamatera@hotmail.com,rcpereira03091988@gmail.com,kazumi.s@gmail.come phfelber@hotmail.com

Revista Brasileira de Milho e Sorgo, v.18, n.2, p. 245-256, 2019

\begin{abstract}
RESUMO - O presente estudo objetivou avaliar o rendimento da cultura e o potencial fisiológico de sementes de milho em resposta a pré-inoculação com Azospirillum brasilense. Quatro doses de inoculante foram aplicadas via tratamento industrial de sementes, 30 dias antes da semeadura. Outros três tratamentos compuseram o ensaio: um contendo metade da recomendação de nitrogênio mineral, o segundo com metade da dose + inoculação momentos antes da semeadura, e um terceiro com a dose total de nitrogênio mineral. Na avaliação da qualidade fisiológica empregaram-se os testes de primeira contagem, germinação, frio modificado, emergência em areia, índice de velocidade de emergência e condutividade elétrica, ao passo que em campo foram avaliados o diâmetro do colmo, massa seca da parte aérea, número de grãos por fileira, número de fileiras por espiga, massa de mil grãos e produtividade. Os delineamentos empregados foram de inteiramente casualizado para qualidade fisiológica e em blocos completos com tratamentos casualizados para ensaio de campo. Independentemente da dose, o inoculante não prejudicou a germinação e vigor das sementes de milho ao longo do armazenamento. Já em relação à produtividade, a inoculação efetuada momentos antes da semeadura assegurou desempenho superior àqueles obtidos quando o inoculante foi aplicado às sementes juntamente com os defensivos. Palavras-chave: Zea mays, fixação biológica, inoculante, adubação.
\end{abstract}

\section{INDUSTRIAL TREATMENT AND PREINOCULATION OF CORN WITH Azospirillum spp.: SEED PHYSIOLOGICAL POTENTIAL AND CROP YIELD}

\begin{abstract}
The present study aimed to evaluate yield and the seed physiological potential of corn crop in response to preinoculation with Azospirillum brasilense. Four doses of the inoculant were industrially applied to seeds. Other three treatments were tested: one using half of the recommendation of mineral nitrogen, a second with half the dose + inoculation just before sowing and finally a third one employing the total dose of mineral nitrogen. To evaluate seed physiological potential, the first count, germination, modified cold test, sand emergence, emergence speed index and electrical conductivity were the tests used; whereas in the field the variables assessed were the stem diameter, shoot dry mass, number of grains per row, number of rows per spike, mass of one thousand grains and grain yield. The experimental designs used were the completely randomized for the physiological quality trial and the complete blocks with randomized treatments for field one. Regardless the dose, the inoculant did not impair seed germination and vigor over storage. Concerning yield, the inoculation performed just before sowing showed higher results than those obtained when the inoculant was jointly applied to seeds with pesticides.
\end{abstract}

Keywords: Zea mays, biological fixation, inoculant, fertilization. 
A cultura do milho (Zea mays) destaca-se como um dos cereais de maior importância econômica do setor agrícola. Com uma produção estimada de aproximadamente 100 milhões de toneladas de grãos de milho na safra 2018/2019, o Brasil ocupa a terceira posição na escala mundial dos principais países produtores de milho (USDA, 2019). Neste contexto, o adequado manejo da fertilidade do solo, incluindo, portanto, o do nitrogênio $(\mathrm{N})$, é fator decisivo para maximizar o potencial produtivo da cultura (Coelho et al., 2004). Todavia, na maioria dos solos brasileiros a disponibilidade de $\mathrm{N}$ tem sido um fator limitante ao cultivo, fato agravado pela adoção de cultivos consecutivos, pela rápida decomposição da matéria orgânica em ambientes tropicais, bem como pelas perdas gasosas ou por lixiviação deste elemento no solo (Hungria et al., 2007).

Para o milho, entretanto, desde os primeiros estudos sobre fixação biológica de $\mathrm{N}$ em gramíneas pelas bactérias de vida livre do gênero Azospirillum (Döbereiner \& Day, 1976), inúmeros são os efeitos benéficos sobre o desempenho produtivo e o aproveitamento do $\mathrm{N}$ reportados na literatura atribuídos à inoculação via sementes ou via sulco de plantio (Hungria et al., 2010; Fukami et al., 2016). Neste cenário, por se constituir uma etapa adicional das operações de pré-plantio, um avanço que promete otimizar o tempo dispendido na inoculação é a aplicação antecipada do inoculante via tratamento industrial, dias antes da semeadura (Araújo et al., 2017).

A este respeito, enquanto para a cultura da soja a inoculação com Bradyrhizobium spp. efetuada simultaneamente à aplicação de fungicidas e inseticidas tem demonstrado ser prejudicial à sobrevivência das bactérias (Campo et al., 2009; Zilli et al., 2010), para o cultivo do milho são escassos os trabalhos que visam a investigar a eficácia do Azospirillum quando aplicado às sementes simultaneamente com defensivos. Neste contexto, o presente estudo se propõe comparar o rendimento da cultura e o potencial fisiológico de sementes de milho obtido com a inoculação via tratamento químico industrial com aqueles obtidos na inoculação padrão, ie.: conduzida momentos antes da semeadura.

\section{Material e Métodos}

Dois experimentos, um em laboratório e outro em campo foram conduzidos. Em ambos, os tratamentos foram constituídos de quatro doses de $A$. brasilense (2, 4, 6 e $8 \mathrm{~g} \mathrm{~kg}^{-1}$ de semente) em formulação polimérica em pó contendo uma concentração de $2 \times 10^{8}$ UFC por grama das estirpes AbV5 e AbV6, consideradas as mais efetivas para a cultura do milho (Hungria et al., 2010). Juntamente com 62,5 mL 100 $\mathrm{kg}^{-1}$ do fungicida metalaxil-m $10 \mathrm{~g} \mathrm{~L}^{-1}+$ fludioxonil $25 \mathrm{~g} \mathrm{~L}^{-1}$ e de $156,25 \mathrm{~mL} 100 \mathrm{~kg}^{-1}$ do inseticida thiamethoxam $350 \mathrm{~g} \mathrm{~L}^{-1}$, as doses de inoculante foram aplicadas sobre as sementes por meio de tratador contínuo por batelada (Cimbria Centricoater CC10).

As sementes, em seguida, foram acondicionadas em sacos de papel kraft, onde foram mantidas por 30 dias em condições ambientais de laboratório (temperatura ambiente média de $22^{\circ} \mathrm{C}$ e umidade relativa média de 66\%), simulando o armazenamento convencional. Outros três tratamentos compuseram o ensaio em campo: um foi conduzido exclusivamente com metade da dose de $\mathrm{N}$-mineral recomendada $(50 \%$ $\mathrm{N}$ ), o segundo foi conduzido com $50 \% \mathrm{~N}$ associado a inoculação momentos antes da semeadura e, por fim, empregou-se um terceiro tratamento em que somente a dose total de $\mathrm{N}(100 \% \mathrm{~N})$ foi fornecida via adubação mineral. A descrição detalhada dos tratamentos é apresentada na Tabela 1. 
Tabela 1. Esquema detalhado dos tratamentos com diferentes doses e modalidades de aplicação de inoculante à base de $A$. brasilense, associados a níveis de adubação com N.

\begin{tabular}{|c|c|c|c|}
\hline Tratamentos & $\begin{array}{c}\text { Adubação } \\
\text { Nitrogenada } \\
\left(\mathrm{kg} \mathrm{ha}^{-1}\right)\end{array}$ & $\begin{array}{c}\text { Dose do } \\
\text { inoculante } \\
\left(\mathrm{g} \mathrm{kg}^{-1}\right) \\
\end{array}$ & Modalidade de inoculação \\
\hline $\mathrm{T} 1 *$ & 90 & 0 & - \\
\hline $\mathrm{T} 2$ & 180 & 0 & - \\
\hline $\mathrm{T} 3$ & 90 & 2 & on farm \\
\hline $\mathrm{T} 4$ & 90 & 2 & \\
\hline T5 & 90 & 4 & 30 dias antes da semeadura \\
\hline T6 & 90 & 6 & \\
\hline $\mathrm{T} 7$ & 90 & 8 & \\
\hline
\end{tabular}

* Sementes não tratadas com inseticida e fungicida para o ensaio em laboratório, mas que, todavia, foram manualmente tratadas para serem semeadas no ensaio de campo.

Para a inoculação on farm, ou seja, aquela realizada momentos antes da semeadura, as sementes foram acondicionadas em sacos plásticos, onde receberam a dosagem descrita na Tabela 1 . Em seguida, a fim de se obter uma distribuição homogênea do produto, as sementes foram agitadas por, aproximadamente, 1 minuto, sem adição de agente adesivo. Nesta etapa, o tempo decorrido entre o tratamento das sementes e a semeadura não ultrapassou $1 \mathrm{~h}$.

A qualidade fisiológica das sementes foi avaliada por meio dos seguintes testes:

Teste de germinação: foi conduzido com oito repetições de 50 sementes para cada tratamento. As sementes foram colocadas para germinar entre três folhas de papel germitest embebidas com água destilada na proporção de 2,5 vezes o peso seco do papel. Foram confeccionados rolos, os quais foram levados para um germinador do tipo Mangelsdorf, regulado para manter constante a temperatura de $25^{\circ} \mathrm{C}$. As avaliações foram realizadas aos quatro (primeira contagem) e aos sete dias (contagem final), computando-se a porcentagem de plântulas normais (Brasil, 2009).

Primeira contagem do teste de germinação: efetuada em conjunto com o teste de geminação, computou-se a porcentagem de plântulas normais obtidas no quarto dia após a semeadura (Brasil, 2009).

Teste de frio modificado: foi conduzido com oito repetições de 50 sementes para cada tratamento. Após a semeadura, como acima descrito no teste de germinação, os rolos confeccionados foram envoltos por sacos plásticos lacrados com fitas adesivas, permanecendo nesta condição por um período de sete dias em uma câmara de germinação do tipo B.O.D regulada à temperatura constante de $10^{\circ} \mathrm{C}$. Em seguida, os rolos foram levados para um germinador do tipo Mangelsdorf $\left(25^{\circ} \mathrm{C}\right)$, onde permaneceram por sete dias, procedendo-se, em seguida, a avaliação. Os resultados foram expressos em porcentagem de plântulas normais de acordo com Brasil (2009).

Condutividade elétrica: foi avaliada utilizando-se quatro repetições de 50 sementes para cada tratamento. Inicialmente, as sementes foram pesadas 
e colocadas em copos plásticos contendo $75 \mathrm{~mL}$ de água deionizada e levadas para B.O.D. regulada à temperatura de $25^{\circ} \mathrm{C}$, por um período de 24 horas. Ao final desse período, efetivou-se a leitura da condutividade elétrica na solução de embebição utilizando-se um condutivímetro digital de bancada (Digimed CD20). Previamente à leitura, a solução de embebição foi levemente agitada com a ajuda de um bastão de vidro. O eletrodo do aparelho foi lavado em água desmineralizada e seco com papel toalha antes de cada medição. O valor indicado pelo aparelho foi anotado e dividido pelo peso obtido de cada repetição. Desse modo, o resultado obtido foi expresso em $\mu \mathrm{S} \mathrm{cm}^{-1} \mathrm{~g}^{-1}$ (Vieira \& Krzyzanowski, 1999).

Índice de velocidade de emergência em areia: foi conduzido com quatro subamostras de 50 sementes para cada tratamento. A areia utilizada foi previamente lavada e colocada em bandejas plásticas. O teste foi realizado em condições de casa de vegetação e a umidade mantida com irrigações moderadas. Foram realizadas anotações diárias do número de plântulas normais emergidas até os 15 dias após a semeadura, de acordo com Nakagawa (1999). Os resultados foram expressos em índice de velocidade de emergência, conforme proposto por Maguire (1962).

Emergência final em substrato de areia: o teste foi realizado simultaneamente ao índice de velocidade de emergência. As plântulas normais emergidas foram contadas aos 15 dias após a semeadura, de acordo com Nakagawa (1999). Os resultados foram expressos em porcentagem de plântulas normais.

O ensaio de campo foi conduzido na Fazenda Experimental de Iguatemi da Universidade Estadual de Maringá (latitude de $23^{\circ} 02^{\prime}$ sul e longitude de $52^{\circ} 04^{\prime}$ a oeste de Greenwich, com altitude média de $509 \mathrm{~m}$ ). O clima predominante na região, segundo Köppen, é do tipo Cfa,. Por meio da estação meteoro- lógica automática localizada na estação experimental foram obtidos os dados climatológicos de precipitação acumulada e as temperaturas máxima e mínima durante o ciclo da cultura (Figura 1).

$\mathrm{O}$ experimento foi instalado em área com histórico de sucessão entre as culturas da soja ou do milho no verão com a do trigo ou canola no inverno. $\mathrm{O}$ solo da área experimental foi classificado como Argissolo Vermelho distroférrico (Santos et al., 2018). Os resultados da análise química e física, na camada de 0-20 cm, antes da implantação do experimento foram: $\mathrm{pH}\left(\mathrm{CaCl}_{2}\right)=4,80, \mathrm{P}$ (Mehlich-1) $=6,18 \mathrm{mg}$ $\mathrm{dm}^{-3}, \mathrm{H}^{+}+\mathrm{Al}^{3+}=4,12 \mathrm{cmolc} \mathrm{dm}^{-3}, \mathrm{Al}^{3+}=0,10 \mathrm{cmolc}$ $\mathrm{dm}^{-3}, \mathrm{~K}+=0,41 \mathrm{cmolc} \mathrm{dm}^{-3}, \mathrm{Ca}^{2+}=2,73 \mathrm{cmolc} \mathrm{dm}^{-3}$, $\mathrm{Mg}^{2+}=1,35 \mathrm{cmolc} \mathrm{dm}^{-3}, \mathrm{CTC}=8,61 \mathrm{cmolc} \mathrm{dm}^{-3} \mathrm{e} \mathrm{V}$ $=52,13 \%$. Em relação à análise granulométrica, para a mesma camada de $0-20 \mathrm{~cm}$ os resultados foram: $14,20 \%$ de areia grossa, 37,3\% de areia fina, 0,95\% de silte e $47,55 \%$ de argila.

Antes da instalação da cultura, a população de bactérias diazotróficas foi previamente quantificada, atendendo os requisitos do Ministério da Agricultura (Brasil, 2011): a partir de cinco subamostras da área experimental, obteve-se uma amostra composta da profundidade de $0-10 \mathrm{~cm}$, a qual foi em seguida acondicionada em saco plástico e mantida em caixa térmica e transportada ao laboratório no prazo máximo de $48 \mathrm{~h}$, quando foi submetida a contagem de bactérias diazotróficas seguindo a instrução normativa (Brasil, 2010). Os resultados desta contagem são apresentados na Tabela 2.

Tendo por base a análise do solo e considerando uma expectativa de produtividade de, aproximadamente, $10.000 \mathrm{~kg} \mathrm{ha}^{-1}$ (Pereira Filho, 2015), na base, as adubações fosfatada e potássica foram realizadas mecanicamente com a aplicação de $300 \mathrm{~kg}$ $\mathrm{ha}^{-1}$ do formulado 0-16-16. Adicionalmente, entre os 


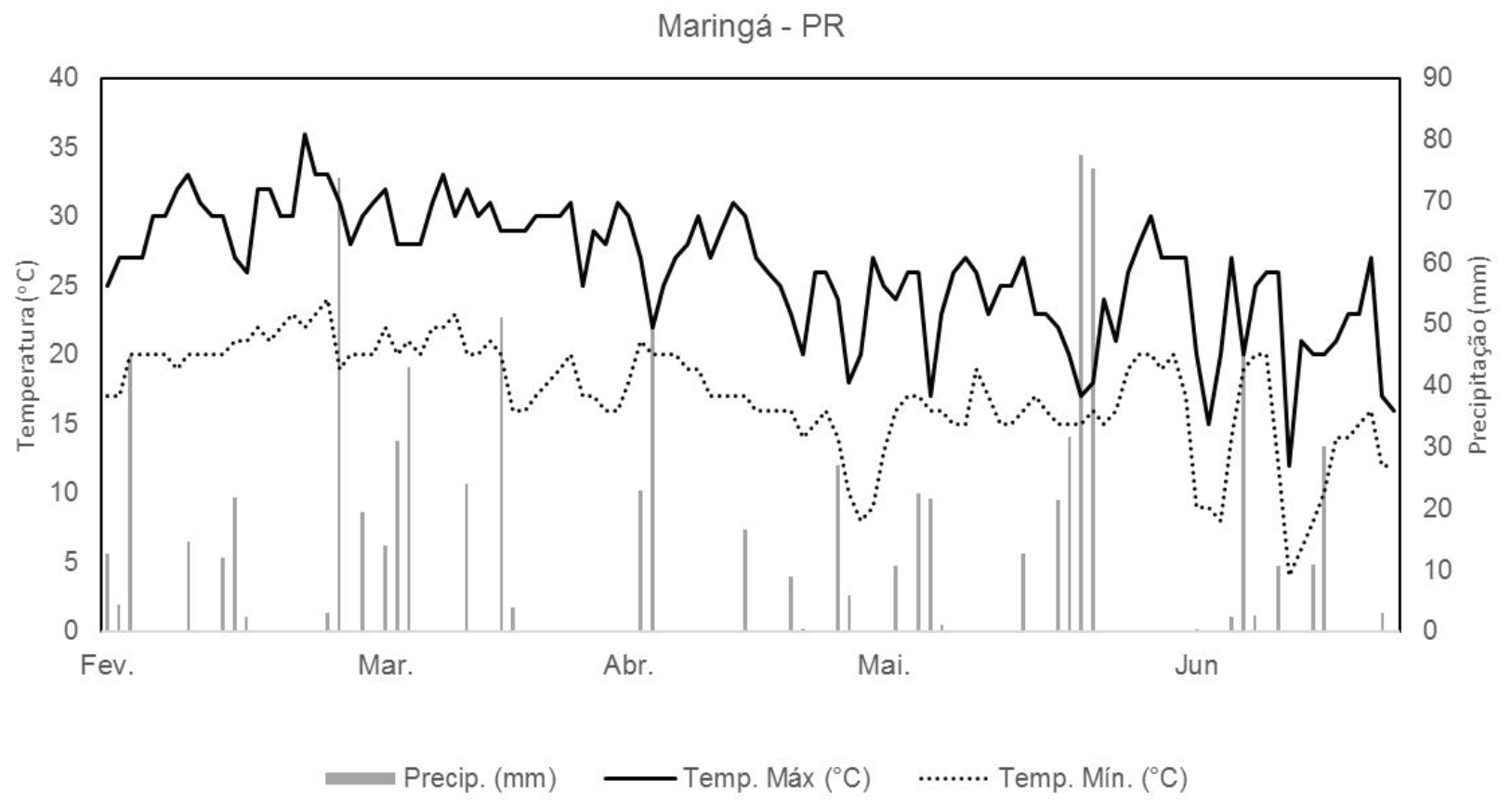

Figura 1. Dados climáticos diários da precipitação pluvial e temperaturas máxima e mínima, de 15 de fevereiro a 26 de junho de 2017, na Fazenda Experimental de Iguatemi, em Maringá-PR, com a cultura do milho segunda safra.

Tabela 2. Resultados da análise de contagem de bactérias diazotróficas da área experimental antes da implantação da cultura do milho (Maringá - PR, 2017).

\begin{tabular}{lccc}
\hline Identificação & $\begin{array}{c}\text { Umidade } \\
\text { do solo }(\%)\end{array}$ & $\begin{array}{c}\text { Bactérias totais } \\
\left(10^{7} \mathrm{UFC} \mathrm{g}^{-1} \text { solo seco }\right)\end{array}$ & $\begin{array}{c}\text { Bactérias diazotróficas } \\
\left(10^{6} \mathrm{UFC} \mathrm{g}^{-1} \text { solo seco }\right)\end{array}$ \\
\hline Amostra 1 & 16,94 & 15,02 & 11,91 \\
\hline
\end{tabular}

UFC - Unidade formadora de colônias.

estádios V5 e V6, $35 \mathrm{~kg}$ de $\mathrm{K}_{2} \mathrm{O}$ ha $^{-1}$ foi aplicado em cobertura empregando-se como fonte o cloreto de potássio. Na adubação nitrogenada, empregou-se a ureia $(45 \%$ de $\mathrm{N})$, de maneira a fornecer a dose total reco-

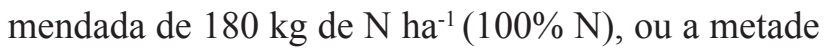
desta $(50 \% \mathrm{~N})$, de acordo com o descrito na Tabela 1 . Em ambos os casos, 1/3 da adubação mineral nitrogenada foi realizada no plantio, enquanto que o restante, $2 / 3$, foi manualmente aplicado em cobertura no estádio V4.
O sistema de semeadura adotado foi o direto, sem irrigação. A área experimental foi dessecada 15 dias antes da semeadura com o herbicida Glyphosate (2,5 $\left.\mathrm{L} \mathrm{ha}^{-1}\right)$ associado a 2,4-D-dimetilamina (1 L ha-1) e ao óleo mineral $\left(0,5 \mathrm{~L} \mathrm{ha}^{-1}\right)$. Durante o cultivo foram realizadas capinas manuais e aplicações do herbicida Atrazina (5 L ha-1) e Tembotriona (200 mL ha-1). A semeadura foi realizada em 15 de fevereiro de 2017 com uma densidade de, aproximadamente, quatro plantas viáveis por metro linear. As parcelas experi- 
mentais foram compostas de sete linhas de seis metros, espaçadas de $0,45 \mathrm{~m}$, atendendo as normas para avaliação da eficiência agronômica de inoculantes do Ministério da Agricultura (Brasil, 2011). Na colheita foram eliminadas 2 linhas externas de cada lado da parcela e 0,5 m de bordadura das linhas centrais.

Para determinação da massa seca de parte aérea, no estádio R1, 5 plantas por parcela foram aleatoriamente coletadas, etiquetadas e, a seguir, transportadas para o laboratório, onde foram acondicionadas em sacos de papel kraft e levadas para secar em estufa com circulação forçada de ar a $65^{\circ} \mathrm{C}$ até atingirem peso constante. Para as variáveis número de grãos por fileira e número de fileiras por espiga, no ponto de maturidade fisiológica completa, foram coletadas aleatoriamente 5 espigas por parcela para posterior contagem em laboratório. Neste mesmo estádio fisiológico, caracterizado por $95 \%$ das sementes apresentando formação da camada preta, a área útil das parcelas foi manualmente colhida e as espigas obtidas foram debulhadas em máquina debulhadora estacionária, obtendo-se, desta forma, uma massa de sementes que foi limpa com o auxílio de peneiras manuais. A partir da massa limpa de grãos, a produtividade foi obtida por meio de pesagem em balança analítica. O peso dos grãos foi corrigido para $13 \%$ de umidade, calculando-se posteriormente o rendimento de grãos em $\mathrm{kg} \mathrm{ha}^{-1}$.

O peso de mil grãos foi determinado pela pesagem de oito subamostras de 100 grãos para cada repetição de campo, com auxílio de balança analítica com precisão de um miligrama. Em seguida, obedecendo ao critério do coeficiente de variação inferior a quatro, os resultados foram multiplicados por 10 , de acordo com Brasil (2009).

$\mathrm{O}$ experimento em laboratório foi conduzido adotando-se o delineamento experimental inteira- mente casualizado, com quatro repetições, ao passo que para o ensaio de campo foi adotado o delineamento em blocos completos com tratamentos casualizados, também com quatro repetições. Os dados das variáveis respostas foram submetidos à análise de variância, mediante o atendimento das pressuposições básicas (erros normalmente distribuídos com média zero e variância em comum). Para tal, utilizaram-se os testes de Shapiro-Wilk para teste da normalidade e Levene para a homogeneidade de variâncias (Banzatto \& Kronka, 2008).

Os resultados da primeira contagem, germinação, teste de frio modificado e emergência final em substrato de areia apresentaram heterogeneidade de variâncias e foram, portanto, previamente transformados em arcsen. Todavia, nas tabelas foram empregadas somente as médias originais. Quando o tratamento foi significativo, as médias foram comparadas pelo teste de Scott-Knott, a 5\% de probabilidade.

\section{Resultados e discussão}

Em relação as análises de qualidade fisiológica das sementes, observa-se que a testemunha não tratada (T1) apresentou valores superiores de germinação e vigor, indicando, portanto, a existência de um efeito adverso do tratamento com fungicida e inseticida sobre o potencial fisiológico das sementes (Tabela 3). Todavia todos os tratamentos testados, independentemente da dose de inoculante e do tratamento químico, apresentaram-se aptos para comercialização, uma vez que as médias de plântulas normais se encontram acima do padrão mínimo de $85 \%$, estabelecido como garantia mínima para a comercialização de sementes de milho híbrido no país (Brasil, 2013). 
Tabela 3. Resultados médios das avaliações de qualidade fisiológica do híbrido de milho Formula TL, em resposta as diferentes doses do inoculante aplicado via tratamento industrial 30 dias antes da semeadura: primeira contagem (PC), germinação (G), teste de frio modificado (TFM), emergência final em substrato de areia (EM), índice de velocidade de emergência (IVE) e condutividade elétrica (CE).

\begin{tabular}{ccccccc}
\hline Tratamentos & PC (\%) & G $(\%)$ & TFM (\%) & EM (\%) & IVE & $\begin{array}{c}\text { CE } \\
\left(\mu \mathrm{cm}^{-1} \mathrm{~g}^{-1}\right)\end{array}$ \\
\hline T1 & $98,00 \mathrm{~A}$ & $98,00 \mathrm{~A}$ & $95,50 \mathrm{~A}$ & $95,00 \mathrm{~A}$ & $8,20 \mathrm{~A}$ & $10,24 \mathrm{D}$ \\
T2 & $90,50 \mathrm{~B}$ & $96,00 \mathrm{~B}$ & $90,50 \mathrm{~B}$ & $93,00 \mathrm{~A}$ & $8,47 \mathrm{~A}$ & $10,13 \mathrm{D}$ \\
T3 & $90,25 \mathrm{~B}$ & $95,00 \mathrm{~B}$ & $90,50 \mathrm{~B}$ & $94,00 \mathrm{~A}$ & $8,57 \mathrm{~A}$ & $10,40 \mathrm{D}$ \\
T4 & $88,00 \mathrm{~B}$ & $96.50 \mathrm{~B}$ & $91,00 \mathrm{~B}$ & $93,00 \mathrm{~A}$ & $7,98 \mathrm{~B}$ & $11,58 \mathrm{C}$ \\
T5 & $87,00 \mathrm{~B}$ & $95,00 \mathrm{~B}$ & $91,00 \mathrm{~B}$ & $92,00 \mathrm{~A}$ & $7,89 \mathrm{~B}$ & $16,46 \mathrm{~B}$ \\
T6 & $86,75 \mathrm{~B}$ & $95,50 \mathrm{~B}$ & $89,00 \mathrm{~B}$ & $94,00 \mathrm{~A}$ & $7,81 \mathrm{~B}$ & $17,19 \mathrm{~A}$ \\
T7 & $87,00 \mathrm{~B}$ & $94,50 \mathrm{~B}$ & $91,50 \mathrm{~B}$ & $93,50 \mathrm{~A}$ & $7,71 \mathrm{~B}$ & $17,62 \mathrm{~A}$ \\
\hline Média & 89,64 & 95,79 & 91,29 & 93,50 & 8,09 & 13,37 \\
CV (\%) & 7,05 & 6,24 & 8,18 & 9,33 & 7,04 & 5,34 \\
\hline
\end{tabular}

T1: testemunha (sementes não tratadas);

T2: sementes tratadas (fungicida + inseticida);

T3: sementes tratadas + inoculação on farm na dose de $2 \mathrm{~g} \mathrm{~kg}^{-1}$;

T4: sementes tratadas + pré-inoculação na dose de $2 \mathrm{~g} \mathrm{~kg}^{-1}$;

T5: sementes tratadas + pré-inoculação na dose de $4 \mathrm{~g} \mathrm{~kg}^{-1}$;

T6: sementes tratadas + pré-inoculação na dose de $6 \mathrm{~g} \mathrm{~kg}^{-1}$;

T7: sementes tratadas + pré-inoculação na dose de $8 \mathrm{~g} \mathrm{~kg}^{-1}$

Médias seguidas de mesma letra maiúscula na coluna não diferem estatisticamente pelo teste de Scott-Knott, em nível de 5\% de probabilidade.

No teste de emergência em areia, não se observaram diferenças estatísticas entre nenhum dos sete tratamentos testados (Tabela 3). A este respeito, Marcos Filho et al. (2009) apontam que, frequentemente, lotes de elevada qualidade inicial apresentaram menor flutuação no porcentual de plântulas emergidas em areia, sobretudo porque, diferentemente dos testes em que o papel é o substrato, na emergência, a areia atenua a concentração dos ingredientes ativos próximos as sementes (Taylor \& Salanenka, 2012), reduzindo a sensibilidade do teste na distinção do vigor. Por outro lado, com exceção da testemunha não tratada (T1), que apre- sentou resultados superiores nas variáveis primeira contagem, germinação e teste de frio modificado, os demais tratamentos foram estatisticamente equivalentes entre si (Tabela 3), confirmando, portanto, a existência de efeito neutro da dose do inoculante sobre as sementes.

Embora o número de plântulas normais tenha sido equivalente entre todos os tratamentos no teste de emergência em substrato de areia (Tabela 3), os tratamentos T1 (testemunha), T2 (semente tratada) e T3 (semente tratada + inoculação on farm na dose de $2 \mathrm{~g} \mathrm{~kg}$-1) apresentaram maior índice de velocidade de emergência (Tabela 3). 
Fato confirmado pelo teste de condutividade elétrica (Tabela 3), em que para este mesmo trio de tratamentos observou-se qualidade fisiológica superior.

Em relação ao diâmetro de colmo e a matéria seca da parte aérea (Tabela 4), resultados superiores foram observados quando metade da dose de $\mathrm{N}$ mineral foi usada em combinação com a inoculação momentos antes do tratamento (T3), enquanto que os piores desempenhos nessas variáveis foram observados no tratamento $\mathrm{T} 1$ (testemunha $+90 \mathrm{~kg} \mathrm{~N} \mathrm{ha}^{-1}$ ), em que somente metade do $\mathrm{N}$ mineral foi fornecido à cultura. Todavia, enquanto para o diâmetro do col- mo os tratamentos pré-inoculados (T4, T5, T6 e T7) apresentaram valores equivalentes à $\mathrm{T} 2$ (sementes tratadas $+180 \mathrm{~kg} \mathrm{~N} \mathrm{ha}^{-1}$ ), na matéria seca da parte aérea os mesmos apresentaram valores inferiores a este último. Por outro lado, não se observaram diferenças estatísticas entre os tratamentos pré-inoculados (T4, T5, T6 e T7) tanto para o diâmetro do colmo como para matéria seca da parte aérea (Tabela 4).

Para as variáveis número de grãos por fileira e número de fileiras por espiga (Tabela 4) comportamentos similares ao supracitado foram observados, pois ambos os tratamentos T2 (sementes tratadas $+180 \mathrm{~kg}$

Tabela 4. Resultados médios dos componentes de produtividade do híbrido de milho Formula TL, em resposta as diferentes doses do inoculante aplicado via tratamento industrial 30 dias antes da semeadura: diâmetro do colmo (DC), massa seca da parte aérea (MSPA), número de grãos por fileira (NGF) e número de fileiras por espiga (NFE), massa de mil grãos (MMG) e produtividade (PROD).

\begin{tabular}{ccccccc}
\hline Tratamentos & DC $(\mathrm{mm})$ & MSPA $(\mathrm{g})$ & NGF & NFE & PMS (g) & $\begin{array}{c}\text { PROD } \\
\left(\mathrm{Kg} \mathrm{ha}^{-1}\right)\end{array}$ \\
\hline T1 & $8,27 \mathrm{C}$ & $85,57 \mathrm{D}$ & $29,73 \mathrm{C}$ & $13,90 \mathrm{C}$ & $169,98 \mathrm{D}$ & $7307,03 \mathrm{D}$ \\
T2 & $12,55 \mathrm{~B}$ & $115,68 \mathrm{~B}$ & $33,19 \mathrm{~A}$ & $17,34 \mathrm{~A}$ & $190,34 \mathrm{~B}$ & $9260,07 \mathrm{~B}$ \\
T3 & $13,08 \mathrm{~A}$ & $120,57 \mathrm{~A}$ & $31,55 \mathrm{~A}$ & $17,59 \mathrm{~A}$ & $199,55 \mathrm{~A}$ & $9885,79 \mathrm{~A}$ \\
T4 & $12,41 \mathrm{~B}$ & $110,06 \mathrm{C}$ & $30,41 \mathrm{~B}$ & $15,41 \mathrm{~B}$ & $178,15 \mathrm{C}$ & $8769,95 \mathrm{C}$ \\
T5 & $12,03 \mathrm{~B}$ & $107,53 \mathrm{C}$ & $30,37 \mathrm{~B}$ & $15,27 \mathrm{~B}$ & $175,40 \mathrm{C}$ & $8834,76 \mathrm{C}$ \\
T6 & $12,53 \mathrm{~B}$ & $105,01 \mathrm{C}$ & $30,15 \mathrm{~B}$ & $15,10 \mathrm{~B}$ & $177,24 \mathrm{C}$ & $8669,68 \mathrm{C}$ \\
T7 & $12,35 \mathrm{~B}$ & $101,16 \mathrm{C}$ & $30,23 \mathrm{~B}$ & $14,90 \mathrm{~B}$ & $179,98 \mathrm{C}$ & $8764,38 \mathrm{C}$ \\
\hline Média & 11,89 & 106,51 & 30,80 & 15,79 & 181,52 & 8678,09 \\
CV (\%) & 21,12 & 12,84 & 17,45 & 15,56 & 16,34 & 15,86 \\
\hline
\end{tabular}

T1: testemunha (sementes não tratadas) $+90 \mathrm{~kg} \mathrm{~N} \mathrm{ha}^{-1}$;

T2: sementes tratadas (fungicida + inseticida) $+180 \mathrm{~kg} \mathrm{~N} \mathrm{ha}^{-1}$;

T3: sementes tratadas + inoculação on farm na dose de $2 \mathrm{~g} \mathrm{~kg}^{-1}+90 \mathrm{~kg} \mathrm{~N} \mathrm{ha}^{-1}$;

T4: sementes tratadas + pré-inoculação na dose de $2 \mathrm{~g} \mathrm{~kg}^{-1}+90 \mathrm{~kg} \mathrm{~N} \mathrm{ha}^{-1}$;

T5: sementes tratadas + pré-inoculação na dose de $4 \mathrm{~g} \mathrm{~kg}^{-1}+90 \mathrm{~kg} \mathrm{~N} \mathrm{ha}^{-1}$;

T6: sementes tratadas + pré-inoculação na dose de $6 \mathrm{~g} \mathrm{~kg}^{-1}+90 \mathrm{~kg} \mathrm{~N} \mathrm{ha}^{-1}$;

T7: sementes tratadas + pré-inoculação na dose de $8 \mathrm{~g} \mathrm{~kg}^{-1}+90 \mathrm{~kg} \mathrm{~N} \mathrm{ha}^{-1}$;

Médias seguidas de mesma letra maiúscula na linha e minúscula na coluna não diferem estatisticamente pelo teste de Scott-Knott, ao nível de $5 \%$ de probabilidade. 
$\mathrm{N} \mathrm{ha}^{-1}$ ) e T3 ( sementes tratadas + inoculação on farm na dose de $2 \mathrm{~g} \mathrm{~kg}^{-1}+90 \mathrm{~kg} \mathrm{~N} \mathrm{ha}^{-1}$ ) destacaram-se positivamente sobre os demais, ao passo que os menores valores foram registrados quando se empregou apenas a metade da dose de $\mathrm{N}$ mineral associada a pré-inoculação (T4,T5,T6 e T7). Novamente, os tratamentos submetidos a pré-inoculação não apresentaram diferenças estatísticas entre si, apesar das diferentes doses de inoculante empregadas (Tabela 4).

Tanto na massa de mil grãos como na produtividade, desempenho superior foi observado no tratamento em que a inoculação foi realizada momentos antes da semeadura + metade da dose de $\mathrm{N}$ mineral (T3), seguido pelo manejo em que se aplicou a recomendação total de N mineral (T2).

Entretanto, os resultados superiores do tratamento inoculado momentos antes da semeadura demonstram que ao longo de 30 dias de armazenamento a associação do fungicida metalaxil-m + fludioxonil com o inseticida thiamethoxam teve efeito adverso sobre o desempenho do Azospririllum spp. em campo. Todavia, face aos resultados da Tabela 4, é plausível sugerir que parte das células bacterianas foi capaz de sobreviver nas sementes de milho ao longo dos 30 dias de armazenamento, uma vez que a produtividade dos tratamentos pré-inoculados (T4, T5, T6 e T7) foi superior àquela observada quando somente metade da dose de $\mathrm{N}$ mineral foi empregada (T1). O comportamento superior dos tratamentos inoculados, em comparação ao não inoculado (T1), não pode ser exclusivamente atribuído a fixação biológica de $\mathrm{N}$ atmosférico pelas bactérias, mas sobretudo aos seus efeitos indiretos que incluem a produção de hormônios vegetais (Döbereiner \& Day, 1976; Tien etal., 1979; Dobbelaere etal., 1999), que dentre outras coisas, estimulam o crescimento do sistema radicular (Hungria et al., 2010; Fukami et al., 2016), aumentando, portanto, as taxas de absorção de água e nutrientes.

Diferentemente do milho, na cultura da soja a estratégia de pré-inoculação tem sido mais intensamente estudada. Neste sentido, Campo et al. (2009) e Zilli et al. (2010) observaram que sementes recobertas simultaneamente com fungicidas e Bradyrhizobium spp. produziram plantas com menores número e massa de nódulos. Contudo, quando a inoculação foi realizada uma hora antes da semeadura, os efeitos negativos dos ingredientes ativos usados sobre a nodulação foram desprezíveis. Reforçam esta constatação os resultados de Silva Júnior et. al. (2016) e Araújo et al. (2017), os quais, igualmente trabalhando com inoculação do rizóbio em sementes de feijão e soja, respectivamente, encontraram resultados inferiores de produtividade em sementes pré-inoculadas via tratamento industrial efetuado 30 dias antes da semeadura. Entretanto, quando agentes osmo-protetores de células bacterianas são utilizados como veículos de aplicação (Hartley et al., 2012), autores como Silva Junior et al. (2016) e Araújo et al. (2017) obtiveram resultados de produtividade equivalentes entre os tratamentos préinoculado (30 dias antes) e inoculado on farm.

No presente trabalho, ainda que doses de inoculante superiores à recomendada $\left(2 \mathrm{~g} \mathrm{~kg}^{-1)}\right.$ tenham sido empregadas, a aplicação antecipada de Azospirillum spp. comprometeu a eficácia da fixação biológica e, portanto o desempenho da cultura. Efeitos que, segundo Silva Junior et al. (2016) e Araújo et al. (2017), podem ser atribuídos à alta mortalidade das células bacterianas quando associadas à aplicação de defensivos. Todavia, uma vez que o inoculante não comprometeu o potencial fisiológico das sementes, tais resultados não são desencorajadores, pois possibilitam a realização de futuras investigações com a 
inclusão de osmo-protetores bacterianos no tratamento industrial.

\section{Conclusão}

Independentemente da dose, o inoculante não prejudicou a germinação e o vigor das sementes de milho ao longo do armazenamento. Já em relação a produtividade, a inoculação efetuada momentos antes da semeadura assegurou desempenho superior àqueles obtidos quando o inoculante foi aplicado às sementes juntamente com os defensivos.

\section{Agradecimentos}

O presente trabalho foi realizado com apoio financeiro da Coordenação de Aperfeiçoamento de Pessoal de Nível Superior através do Programa de Excelência Acadêmica (CAPES-PROEX).

\section{Referências}

ARAÚJO, R. S.; CRUZ, S. P. da; SOUCHIE, E. L.; MARTIN, T. N.; NAKATANI, A. S.; NOGUEIRA, M. A.; HUNGRIA, M. Preinoculation of soybean seeds treated with agrichemicals up to 30 days before sowing: technological innovation for large-scale agriculture. International Journal of Microbiology, London, v. 2017, n. 1, p. 1-11, 2017.

DOI: $10.1155 / 2017 / 5914786$.

BANZATTO, D. A.; KRONKA, S. N. Experimentação agrícola. 4. ed. Jaboticabal: FUNEP, 2008. 237 p.

BRASIL. Ministério da Agricultura, Pecuária e Abastecimento. Instrução normativa $\mathrm{n}^{\circ} 13$, de 24 de março de 2011. Aprova as normas sobre especificações, garantias, registro, embalagem e rotulagem dos inoculantes destinados à agricultura, bem como as relações dos microrganismos autorizados e recomendados para produção de inoculantes no Brasil. Diário Oficial da União, Brasília, DF, 25 mar. 2011. Seção 1, n. 58, p. 3-7.

BRASIL. Ministério da Agricultura, Pecuária e Abastecimento. Instrução normativa $\mathrm{n}^{\circ} 30$, de 12 de novembro de 2010. Métodos oficiais para análise de inoculantes, sua contagem, identificação e análise de pureza. Diário Oficial da União, Brasília, DF, 17 nov. 2010. Seção 1, p. 4-10.

BRASIL. Ministério da Agricultura, Pecuária e Abastecimento. Instrução normativa $\mathrm{n}^{\circ} 45$, de 17 de setembro de 2013. Padrões para produção e comercialização de sementes de soja. Diário Oficial da União, Brasília, DF, 20 set. 2013. Seção 1, n. 183, p. 6.

BRASIL. Ministério da Agricultura, Pecuária e Abastecimento. Secretaria de Defesa Agropecuária. Regras para análise de sementes. Brasília, DF, 2009. 395 p.

CAMPO, J. R.; ARAÚJO, R. S.; HUNGRIA, M. Nitrogen fixation with the soybean crop in Brazil: compatibility between sedd treatment with fungicides and bradyrhizobial inoculants. Symbiosis, Dordrecht, v. 48, n.1/3, p. 154-163, 2009.

DOI: 10.1007/BF03179994.

COELHO, A. M.; CRUZ, J. C.; PEREIRA FILHO, I. A. Desafios para a obtenção de altas produtividades de milho. Sete Lagoas: Embrapa Milho e Sorgo, 2004. 20 p. (Embrapa Milho e Sorgo. Comunicado Técnico, 99).

DOBBELAERE, S.; CROONENBORGHS, A.; TRYS, A.; VANDE BROEK, A.; VANDERLEYDEN, J. Phytostimulatory effect of Azospirillum brasilense wild type and mutant strains altered in IAA production on wheat. Plant and Soil, The Hague, v. 212, n. 2, p. 155-164, 1999. DOI: 10.1023/A:1004658000815.

DÖBEREINER, J.; DAY, J. M. Associative symbioses in tropical grasses: characterization of microorganisms and dinitrogen-fixing sites. In: INTERNATIONAL SYMPOSIUM ON NITROGEN FIXATION, 1., 1976, Washington. Proceedings... Washington: Washington State University Press, 1976. p. 518-538. 
FUKAMI, J.; NOGUEIRA M. A.; ARAÚJO, R. S.; HUNGRIA, M. Accessing inoculation methods of maize and wheat with Azospirillum brasilense. AMB Express, Münster, v. 6, n. 3, p. 2-13, 2016.

DOI: $10.1186 / \mathrm{s} 13568-015-0171-\mathrm{y}$.

HARTLEY, E. J.; GEMELL, L. G.; DEAKER, R. Some factors that contribute to poor survival of rhizobia on preinoculated legume seed. Crop \& Pasture Science, Victoria, v. 63, n. 9, p. 858-865, 2012.

DOI: $10.1071 / \mathrm{CP} 12132$.

HUNGRIA, M.; CAMPO, R. J.; MENDES, I. C. A importância do processo de fixação biológica do nitrogênio para a cultura da soja: componente essencial para a competitividade do produto brasileiro. Londrina: Embrapa Soja, 2007. 80 p. (Embrapa Soja. Documentos, 283). Disponível em: <http://ainfo.cnptia.embrapa.br/ digital/bitstream/item/60593/1/Documentos-283.pdf $>$. Acesso em: 13 abr. 2018.

HUNGRIA, M.; CAMPO, R. J.; SOUZA, E. M. S.; PEDROSA, F. O. Inoculation with selected strains of Azospirillum brasilense and A. lipoferum improves yields of maize and wheat in Brazil. Plant and Soil, The Hague, v. 331, n. 1-2, p. 413-425, 2010.

DOI: $10.1007 / \mathrm{s} 11104-009-0262-0$.

MAGUIRE, J. D. Speed of germination-aid in selection and evaluation for seedlings emergence and vigor. Crop Science, Madison, v. 2, n. 1, p. 176-177, 1962.

DOI: $10.2135 /$ cropsci1962.0011183X000200020033x.

MARCOS FILHO, J.; KIKUTI, A. L. P.; LIMA, L. B. Métodos para avaliação do vigor de sementes de soja, incluindo a análise computadorizada de imagens. Revista Brasileira de Sementes, Londrina, v. 31, n. 1, p. 102-112, 2009.

DOI: $10.1590 / \mathrm{S} 0101-31222009000100012$.

NAKAGAWA, J. Testes de vigor baseados no desempenho das plântulas. In: KRZYZANOWSKI, F. C.; VIEIRA, R. D.; FRANÇA NETO, J. B. (Ed.). Vigor de sementes: conceitos e testes. Londrina: ABRATES, 1999. cap. 2, p. $1-24$.
PEREIRA FILHO, I. A. (Ed.). Cultivo do milho. 9. ed. Sete Lagoas: Embrapa Milho e Sorgo, 2015. (Embrapa Milho e Sorgo. Sistema de Produção, 1). Disponível em: $<<$ https:/www.spo.cnptia. embrapa.br/conteudo?p_p_id=conteudoportlet_ WAR_sistemasdeproducaolf6_1ga1ceportlet\&p_p_ lifecycle $=0 \& p \_p \_s t a t e=$ normal $\& p \_p \_$mode $=v i e w \& p \_p \_$ col_id=column-2\&p_p_col_count=1\&p_r_p_ 6293187 _ sistemaProducaoId=7905\&p_r_p_-996514994_ topicoId $=8658>$. Acesso: 14 abr. 2018.

SANTOS, H. G. dos; JACOMINE, P. K. T.; ANJOS, L. H. C. dos; OLIVEIRA, V. A. de; LUMBRERAS, J. F.; COELHO, M. R.; ALMEIDA, J. A. de; ARAÚJO FILHO, J. C. de; OliVEIRA, J. B. de; CUNHA, T. J. F. Sistema Brasileiro de Classificação de Solos. 5. ed. rev. e ampl. Brasília, DF: Embrapa, 2018.

SILVA JÚNIOR, E. B.; OLIVEIRA, S. S.; MARTINS, L. V. M.; OLIVEIRA, P. J.; ZILLI, J. E.; BODDEY, R. M.; XAVIER, G. R. Pré-inoculação de sementes de Vigna unguiculata (L) Walp. com inoculante polimérico no centro-oeste. Pesquisa Agropecuária Pernambucana, Recife, v. 21, n. 1, p. 39-42, 2016.

DOI: $10.12661 /$ pap.2016.007.

TAYLOR, A. G.; SALANENKA, Y. A. Seed treatments: phytotoxicity amelioration and Tracer uptake. Seed Science Research, Cambridge, v. 22, n. S1, p. 86-90, 2012. DOI: $10.1017 / \mathrm{S} 0960258511000389$.

TIEN, T. M.; GASKIN, M. H.; HUBBEL, D. H. Plant growth substances produced by Azospirillum brasilense and their effect on the growth of pearl millet (Pennisetum americanum L.). Applied and Environmental Microbiology, Washington, v. 37, n. 5, p. 1016-1024, 1979.

USDA. United States Department of Agriculture. World agricultural production. Washington, 2019. 31 p. (Circular Series WAP 5-19). Disponível em: <https://apps. fas.usda.gov/psdonline/circulars/production.pdf $>$. Acesso em: 28 maio 2019.

VIEIRA, R. D.; KRZYZANOWSKI, F. C. Teste de condutividade elétrica. In: KRZYZANOWSKI, F. C.; 
VIEIRA, R. D.; FRANÇA NETO, J. B. (Ed.). Vigor de sementes: conceitos e testes. Londrina: ABRATES, 1999. cap. 4, p. 1-26.

ZILLI, J. E.; CAMPO, R. J.; HUNGRIA, M. Eficácia da inoculação de Bradyrhizobium em pré-semeadura da soja. Pesquisa Agropecuária Brasileira, Brasília, v. 45, n. 3, p. 335-338, 2010.

DOI: 10.1590/S0100-204X2010000300015. 